\title{
Supplement Consumption among Post stroke Patients in Dr. Hasan Sadikin General Hospital Bandung
}

\author{
Annisa Rahayu, ${ }^{1}$ Novitri, ${ }^{2}$ Novi Vicahyani Utami ${ }^{3}$ \\ ${ }^{1}$ Faculty of Medicine Universitas Padjadjaran, ${ }^{2}$ Department of Physical Medicine and \\ Rehabilitation Faculty of Medicine, Universitas Padjadjaran/Dr. Hasan Sadikin General Hospital \\ Bandung, ${ }^{3}$ Department of Pharmacology and Therapy Faculty of Medicine \\ Universitas Padjadjaran
}

\begin{abstract}
Background: Stroke is one of the leading causes of global disability. Post stroke rehabilitation program becomes the key to gain functional recovery. Thus it minimizes disabilities. Multiple studies have been carried out to gain greater functional outcomes for post stroke patients, including medical therapy such as supplements. However, supplement effectiveness in providing stroke recovery or prevention is still debatable. There is no data of supplement consumption among post stroke patients; therefore, the aim of this study was to determine the supplement consumption among post stroke patients.

Methods: This study was a cross sectional descriptive study using primary data with a consecutive sampling method. Minimum samples for this study were 42 post stroke respondents who followed rehabilitation program. This study was conducted at Physical Medicine and Rehabilitation Clinic of Dr. Hasan Sadikin General Hospital Bandung from June until November 2013. The interviews were done after written informed consent was obtained. Descriptive statistics such as frequency distributin and proportion were used to analyze the data.

Results: From 42 respondents, 23 (55\%) respondents consumed the supplement. From 34 supplements recorded, 56\% were herbs supplements; followed by multivitamin (29\%), mineral (6\%), multivitamin and mineral $(6 \%)$, and other supplement $(3 \%)$. The most frequent ingredients composed in the supplements were B1, B6 and B12 vitamin (7\%).

Conclusions: More than a half of post stroke patients at Physical Medicine and Rehabilitation Clinic Dr. Hasan Sadikin General Hospital are supplement users, with herbal supplements as the majority. The most frequent ingredients used are B1, B6 and B12 vitamin. [AMJ.2016;3(3):452-9]
\end{abstract}

Keywords: Herbal supplements, post stroke, supplement consumption

\section{Introduction}

A great number of new stroke events every year unwittingly steps up the total number of post stroke patients. Stroke sequelae, disabilities, handicaps, and recurrence events become the burden for these stroke survivors. ${ }^{1}$ From 15 million people who suffer a stroke annually, one third leftward is permanently disabled. ${ }^{2}$ Disability is the lack of ability to perform an activity or task in the range considered normal for a human being. ${ }^{3}$ Maximizing the functional recovery after stroke event is the main key to minimize the burden that emerges from disabilities. Recent studies show the existence of neuronal repair after stroke, such as neurogenesis, reorganization, and axonal sprouting., ${ }^{4}$ Early functional recovery takes place on the first few days once the surrounding edema subsided. Later recovery tends to be slower, but progressive, especially with repetitive exercises in rehabilitation program. ${ }^{6,7}$

Rehabilitation programs have become the main approach for stroke recovery in several decades. The primary goals are to prevent complications, minimize impairments, and maximize function. Stroke rehabilitation program consists of physiotherapy, speech and language therapy, occupational therapy, and vocational therapy. ${ }^{8}$ Effective rehabilitation interventions that initiated early after stroke can enhance greater the recovery process and minimize the functional disability. ${ }^{9}$ 
Nowadays, researchers try to improve functional recovery by medical approach, especially by developing dietary supplements. United States Dietary Supplement Health and Education Act (DSHEA) defines dietary supplements as any product (other than tobacco) intend to supplemented the diet that bears or contains one or more: a vitamin, a mineral, a herb or other botanical, an amino acid, a supplement used by man to supplemented the diet by increasing the total dietary intake, or a concentrate, metabolite, constituent, extract, or combination of any ingredient described above. ${ }^{10}$

Not with standing, supplements effectiveness such as vitamin B1, B6, B12, vitamin $\mathrm{D}$, vitamin $\mathrm{E}$, vitamin $\mathrm{K}$, folic acid, fish oil, and calcium for stroke recovery and recurrent prevention are debated. One of the arguments is the effectiveness of consuming vitamin B1, B6 and B12 and folic acid. Saposnik et al. ${ }^{12}$ concludes that lowering of homocysteine with folic acid and vitamin B6 and $\mathrm{B} 12$ reduces the risk of overall stroke, but not stroke severity and disability ${ }^{11}$ while Vitamin Intervention for Stroke Prevention (VISP) trial shows that vitamin B has no effect on cardiovascular risk. ${ }^{12}$

On the other side, supplement manufactures are already marketed and advertised their products to the patients. By massive marketing strategies, the percentage of the United States (US) population who used at least one dietary supplement has increased from $42 \%$ in 1988-1994 to 53\% in 2003-2006. ${ }^{13}$ However, there is still no data about supplement utilization among post stroke patients in Indonesia. This study was conducted to measure the consumption of supplement by post stroke patients in Physical Medicine and Rehabilitation Clinic Dr. Hasan Sadikin General Hospital Bandung.

\section{Methods}

This study was a cross sectional descriptive study with consecutive sampling method. By $15 \%$ precision, 42 respondents were settled as the minimum sample size of this study. The study was conducted in Physical Medicine and Rehabilitation Clinic at Dr. Hasan Sadikin General Hospital from June-November 2013. All post stroke patients of Physical Medicine and Rehabilitation Department, Dr. Hasan Sadikin General Hospital were the population of this study.

Post stroke patients who followed rehabilitation program routinely and came to Physical Medicine and Rehabilitation Clinic were determined as the study subjects. Participation of this study was voluntary and all process performed in this study were approved by Health Research Ethics and Dean of Faculty. Patients who unwilling to participate, incompletely answered the questions, or uncooperative, were excluded from the study.

Before the interviews were conducted, the content of questions was revised and validated to 20 respondents outside the study subjects. The interviews were performed every Tuesday and Thursday at Physical Medicine and Rehabilitation Clinic's waiting room. After the informed consents were obtained, two sections of interview were begun.

First section of interview included the general demographic information such as age, sex, address, occupation, education, stroke diagnosis, history of previous stroke events, date of last stroke events, and phase of stroke (sub-acute or chronic). Then, qualitative measure of supplement consumption question was asked. The second section of interview was given to the respondents who had consumed supplement since the date of first stroke events. For respondents who had never consumed supplement after the events, the interview was ended.

The second section of interview recorded a number of variables related to supplement consumption: category of supplement (vitamin, mineral, herbs, or others), compositions of supplement, people who recommend the supplement, reason for using supplements, and the effect after consuming supplements that felt subjectively.

Frequency of distribution and proportion were calculated. Data were presented in tables and figures.

\section{Results}

This study was participated by 21 (50\%) male and $21(50 \%)$ female. The most common age of respondents was 55-59 years old (23.8\%). One third of respondents were graduated from elementary school. Only $23.8 \%$ were graduated from universities, either with bachelor degree or more. Nearly two third of the respondents were jobless (16.7\% unemployed; $26.2 \%$ housewife; $21.4 \%$ retired).

The majority of the respondents $(88.1 \%)$ were recorded as ischemic stroke patients on the medical records, and $52.4 \%$ were on their first stroke event. According to the natural history of stroke, $61.9 \%$ of respondents were 
Table 1 General Characteristic of Respondents

\begin{tabular}{|c|c|c|}
\hline Variable & Frequency (n) & Percentage (\%) \\
\hline \multicolumn{3}{|l|}{ Sex } \\
\hline Male & 21 & 50 \\
\hline Female & 21 & 50 \\
\hline \multicolumn{3}{|l|}{ Age Category (years old) } \\
\hline $40-44$ & 2 & 4.8 \\
\hline $45-49$ & 5 & 11.9 \\
\hline $50-54$ & 8 & 19.0 \\
\hline $55-59$ & 10 & 23.8 \\
\hline $60-64$ & 5 & 11.9 \\
\hline $65-69$ & 6 & 14.3 \\
\hline $70-74$ & 5 & 11.9 \\
\hline $80-84$ & 1 & 2.4 \\
\hline \multicolumn{3}{|l|}{ Education } \\
\hline Un-graduated Elementary School & 2 & 4.8 \\
\hline Elementary School & 14 & 33.3 \\
\hline Junior High School & 4 & 9.5 \\
\hline Senior High School & 12 & 28.6 \\
\hline College & 10 & 23.8 \\
\hline \multicolumn{3}{|l|}{ Occupation } \\
\hline Unemployed & 7 & 16.7 \\
\hline Housewife & 11 & 26.2 \\
\hline Retirement & 9 & 21.4 \\
\hline Labor & 2 & 4.8 \\
\hline Business & 8 & 19.0 \\
\hline Government Worker & 5 & 11.9 \\
\hline \multicolumn{3}{|l|}{ Diagnosis } \\
\hline Ischemic Stroke & 37 & 88.1 \\
\hline Hemorragic Stroke & 5 & 11.9 \\
\hline \multicolumn{3}{|l|}{ Stroke Event } \\
\hline First & 22 & 52.4 \\
\hline Recurrent & 20 & 47.6 \\
\hline \multicolumn{3}{|l|}{ Stroke Phase } \\
\hline Subacute & 26 & 61.9 \\
\hline Chronic & 16 & 38.1 \\
\hline
\end{tabular}

classified in sub-acute phase (2 weeks to 6 months after stroke event) and 38.1\% in chronic phase (more than 6 months) (Table 1).

After all interviews were performed, the data showed that $23(54.8 \%)$ respondents consumed supplement, while the rest $19(45.2 \%)$ were not. More than half of supplements used by post stroke patients were categorized into herbs supplements (55.8\%), followed by multivitamin supplements 
Annisa Rahayu, Novitri, Novi Vicahyani Utami: Supplement Consumption among Post stroke Patients in Dr. 455 Hasan Sadikin General Hospital Bandung

Table 2 Distribution of Supplements Compositions

\begin{tabular}{|c|c|c|c|}
\hline \multicolumn{2}{|c|}{ Composition } & \multirow{2}{*}{$\frac{\text { Frequency }(\mathrm{n})}{3}$} & \multirow{2}{*}{$\frac{\text { Percentage }(\%)}{4.29}$} \\
\hline Multivitamin & Vitamin A & & \\
\hline & Vitamin B1, B6 and B12 & 5 & 7.14 \\
\hline & Vitamin C & 2 & 2.86 \\
\hline & Vitamin D & 3 & 4.29 \\
\hline & Vitamin E & 2 & 2.86 \\
\hline & Vitamin $\mathrm{K}$ & 1 & 1.43 \\
\hline \multirow[t]{11}{*}{ Mineral } & Calcium & 2 & 2.86 \\
\hline & Chlor & 1 & 1.43 \\
\hline & Copper & 1 & 1.43 \\
\hline & Iodine & 1 & 1.43 \\
\hline & Iron & 1 & 1.43 \\
\hline & Magnesium & 1 & 1.43 \\
\hline & Manganese & 1 & 1.43 \\
\hline & Phosphorus & 1 & 1.43 \\
\hline & Potassium & 2 & 2.86 \\
\hline & Sodium & 1 & 1.43 \\
\hline & Zinc & 1 & 1.43 \\
\hline \multirow[t]{24}{*}{ Herbs } & Akar wangi & 1 & 1.43 \\
\hline & Alfafa & 1 & 1.43 \\
\hline & Aloevera & 1 & 1.43 \\
\hline & Angelicae & 1 & 1.43 \\
\hline & Apple vinegar & 1 & 1.43 \\
\hline & Astragali & 1 & 1.43 \\
\hline & Barley grass & 1 & 1.43 \\
\hline & Brown rice powder & 1 & 1.43 \\
\hline & Chlorella & 1 & 1.43 \\
\hline & Chlorophyll & 1 & 1.43 \\
\hline & Cinnamon & 3 & 4.29 \\
\hline & Cistanchis & 1 & 1.43 \\
\hline & Fish oil & 1 & 1.43 \\
\hline & Dewa leaves & 1 & 1.43 \\
\hline & Epimedii & 1 & 1.43 \\
\hline & Eucommiae & 1 & 1.43 \\
\hline & Gamat stichopus hermanii & 1 & 1.43 \\
\hline & Garcina cambogia & 1 & 1.43 \\
\hline & Garciniae pericarpium & 1 & 1.43 \\
\hline & Ginseng & 2 & 2.86 \\
\hline & Glucosamine sulphate & 1 & 1.43 \\
\hline & Green tea & 1 & 1.43 \\
\hline & Lignum & 1 & 1.43 \\
\hline & Lycii & 1 & 1.43 \\
\hline
\end{tabular}




\begin{tabular}{lccc} 
& Lycii & 1 & 1.43 \\
& Nigella sativa & 3 & 4.29 \\
& Psolarae & 1.43 \\
& Rosela flowers & 1 & 1.43 \\
Other & Spirulina plantesis & 1 & 2.86 \\
Without label composition & White grass & 2 & 1.43 \\
\hline
\end{tabular}

(29.41\%), mineral supplements (5.9\%), multivitamin and mineral supplement (5.9\%), and other supplements (2.9\%) which was choline.

Among 23 supplement users, 34 supplements were recorded in this study. Most common used ingredients were B1, B6 and B12 vitamin. From 34 supplements, there were 5 unknown herbs supplements that had been consumed by respondents and circulated in the market without any label of information on it (Table 2).

The most common given reason for consumption was 'try supplement on in order to gain better health status' (52.9\%). The second most common reason for utilization was 'prescribed by doctor' (38.3\%) (Figure $1)$. Some doctors at Physical Medicine and Rehabilitation Clinic Dr. Hasan Sadikin General Hospital prescribed multivitamin or minerals supplements. The most frequent person or parties who suggested or recommended users to consume supplements were doctors (38.24\%) and relatives (26.47\%) (Figure 2).

From 34 supplements used in this study, $44.12 \%$ supplements led respondents to greater health status, subjectively. Respondents felt that they had a better health condition after consuming supplements such as more energized, mobilization and ambulation improvement, appetite increasing, and decreasing blood pressure. In contrast, respondents who consumed $55.88 \%$ other supplements felt that there was no difference between consuming or not consuming supplements. They feel there was no effect emerged after consuming the supplements.

\section{Discussion}

Demographic information between respondents in this study shows some similarities with Indonesian and South East Asia population. The possibility can be

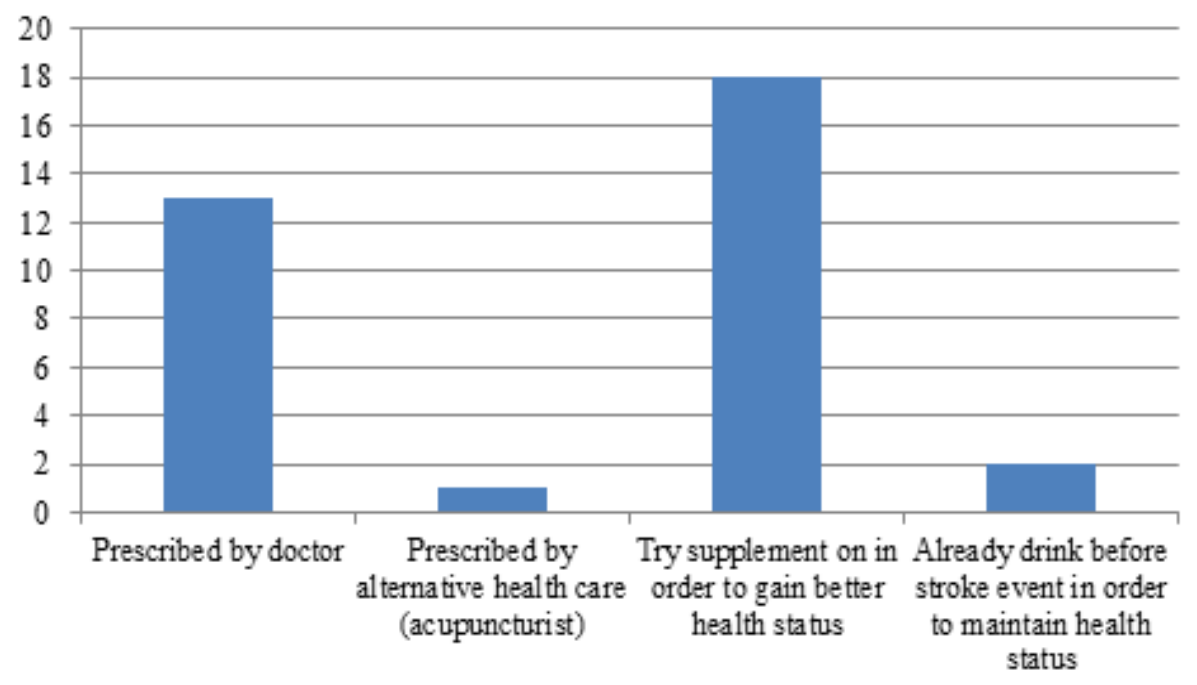

Figure 1 Reasons for using Supplement 


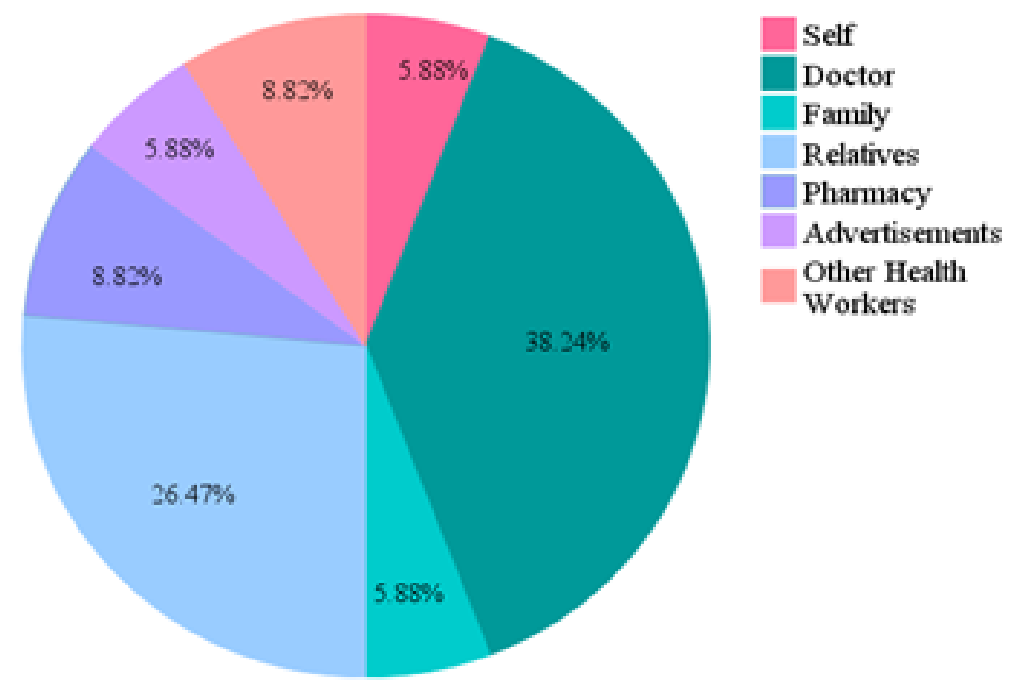

Figure 2 Supplement Consumption Recommendations

relevant to the same race or ethnicity, lifestyle, and behavior. The equal proportion between male $(50 \%)$ and female $(50 \%)$ respondents may represent the sex ratio of stroke patients in Indonesia (male $54.7 \%$ : female $45.3 \%$ ). $^{14}$ The respondent's mean age is 58.1 years old, nearly similar with mean age of South East Asia region stroke patients (59.9 years old). The distribution of stroke diagnosis in the study is dominated by ischemic (infarct) stroke $(88.1 \%)$, just the same as in South East Asia region although with different proportion $(77.7 \%) .{ }^{15}$ Higher mortality rate of hemorrhagic stroke might be the reason behind this phenomenon. ${ }^{16}$

Most respondents in this study were poorly educated; one third of them stopped their formal education after they graduated from elementary school. Moreover, there were still respondents who had not finished elementary school (4.8\%). The preponderance of respondents $(64.3 \%)$ had a low or minimum income (unemployed, housewife, and retirement). This scene could be corresponded with Indonesia's $107^{\text {th }}$ ranking position on Human Development Index United Nations Development Programme (UNDP) 2007 that indicated low health, educational, and income level. ${ }^{17}$ Educational and occupational status might influence respondents' preferences and purchasing power on supplements.

This study showed that more than half of post stroke patients $(54.8 \%)$ consume one or more supplements after their stroke event. There is no data explain about supplement use among post stroke patients, either in Indonesia nor global. The finding in this study is nearly compatible to some other study results, such as data collected by the Food and Drug Administration (FDA) that indicated $55 \%$ of the adults surveyed used some type of dietary supplements; and National Health and Nutrition Examination Survey (NHANES) data collected from 2003 to 2006 that covered all types of dietary supplements indicated 53\% of American adults took at least one dietary supplement, which mostly used multivitamin/ mineral supplement. ${ }^{13}$

The most common used supplements by post stroke patients in this study were categorized into herbs supplements (55.8\%), followed by multivitamin supplements (29.41\%). There was no previous data measured herbs supplements utilization among stroke patients. But, according to the 2007 National Health Interview Survey, which included questions on Americans' use of natural products (exclude vitamins and minerals), 17.7 percent of American adults had used these types of products in the past 12 months. ${ }^{10,18}$

The most common herbs composed in the herbs supplements of this study were Nigella sativa, cinnamon, ginseng, and spirulina. Study in Pakistan ${ }^{19}$ found that Nigella sativa produced antiatherogenic effect by decreasing lipoprotein cholesterol level and increased high density lipoprotein level. Medicinal Plants of Asia and The Pacific mentioned that cinnamon had an anti-spasmodic and 
anti-diabetic effects. Foster et al. ${ }^{20}$ concludes in their book that ginseng prevents platelet aggregation, improves physical performance and quality of life. Spirulina is known to have twice much vitamin B12 as liver, in addition to have many other B vitamins, vitamin A and $\mathrm{E}$, and minerals. ${ }^{20}$ These explanations are possibly the reason of high herb supplement used in stroke patients.

Even though herbs supplement was the most frequent supplement used, from all 34 supplements, the most common used ingredients were vitamin B1, B6 and B12. There were several large and small-scale randomized clinical trials assess the effect of vitamin B supplementation on cardiovascular mortality and morbidity, including stroke.

A trial was implemented on 3680 cerebral infarction patients from 1997 to 2001 which given randomized daily dose of $2.5 \mathrm{mg}$ folic acid, $0.4 \mathrm{mg}$ vitamin B12 and $25 \mathrm{mg}$ vitamin B6; or $20 \mu \mathrm{g}, 6 \mu \mathrm{g}$, and $200 \mu \mathrm{g}$ respectively for 2 years. The trial showed that vitamin B had no effect on cardiovascular risk. Women's Antioxidant and Folic Acid Cardiovascular Study (WAFACS) follow up study which assessed the effect of B-vitamins ( $2.5 \mathrm{mg}$ folic acid, $50 \mathrm{mg}$ B6 vitamin and $1 \mathrm{mg}$ vitamin B12) to 5442 women with cardiovascular disease history for median duration of 7.3 years concluded that there was no difference between placebo and active vitamin B treatment groups in terms of myocardial infarction and stroke risks despite an $18.5 \%$ decrease in homocysteine level.12 Saposnik et al. ${ }^{11}$ outcome analysis on Heart Outcomes Prevention Evaluation (HOPE) 2 trial participants concluded that lowering of homocysteine with folic acid and vitamin B6 and $\mathrm{B} 12$ reduced the risk of overall stroke, but not stroke severity and disability.

Most of supplements in this study were purchased over of the counter (OTC), not based on doctor's prescription or suggestion. Relatives including friends and neighbors, family, pharmacy, advertisement, or even health care workers such as nurse and acupuncturist were the agents who informed, recommended, and persuaded respondents to use selected supplements. Only 38\% supplements were suggested by doctor. This tangibility possibly correlates with patients' health seeking behavior. Health seeking behavior is any action undertaken by individuals who perceive themselves to have a health problem or to be ill in order to find an appropriate remedy. Health seeking behavior correlates with age, gender, education, socioeconomic status, geographic and culture, health belief, experience, and satisfaction to quality service received.

Most respondents felt no improvement after using supplements, subjectively. Moreover, from respondents who felt gaining a better health status, there was only one patient who felt improvement in ambulation; which ambulation improvement is one of stroke recovery outcomes. However, respondent's perception did not represent their real health status. Because this study only conducted subjective feelings, so what respondents felt might be just placebo effects, or maybe there was an effect in patients' body but the effect could not be felt.

In conclusion, more than a half of post stroke patients at Physical Medicine and Rehabilitation Clinic in Dr. Hasan Sadikin General Hospital were supplement users. Majority of supplements used were herbs supplements, followed by multivitamin supplements, mineral supplements, multivitamin and mineral supplements, and other. The most frequent ingredients used in this study were vitamin B1, B6, and B12. Most of supplements users in post stroke patients get the supplements over the counter (OTC). Supplements users got all of herbs supplements OTC, while all of the multivitamin supplements were taken from doctor's prescription and pharmacy. One fourth of the herbs supplements in this study were circulated in the market without brand label and information. The most common given reason for supplement consumption was trying supplement in order to gain better health status. But, more than a half of the users did not feel any effect of improvement.

Limitation of this study were the small number of respondents caused by inadequate time in collecting data; and the outcome parameter after consuming supplements that only measure the subjective effects felt by respondents. What respondents felt might be just placebo effects; effects from another medication and rehabilitation treatment, not from supplements; or maybe there was a supplement effect in respondents' body, but the effect could not be felt.

\section{References}

1. Hardie K, Hankey GJ, Jamrozik K, Broadhurst RJ, Anderson C. Ten-year risk of first recurrent stroke and disability after first-ever stroke in the Perth Community Stroke Study. Stroke. 2004;35(3):731-5.

2. WHO. Global burden of stroke. Geneva: World Health Organization; 2004. 
3. Sturm JW, Dewey HM, Donnan GA, Macdonell RAL, McNeil JJ, Thrift AG. Handicap after stroke: how does it relate to disability, perception of recovery, and stroke subtype?: The North East Melbourne Stroke Incidence Study (NEMESIS). Stroke. 2002;33(3):762-8.

4. Carmichael ST. Themes and strategies for studying the biology of stroke recovery in the poststroke epoch. Stroke. 2008;39(4):1380-8.

5. Benowitz LI, Carmichael ST. Promoting axonal rewiring to improve outcome after stroke. Neurobiol Dis. 2010;37(2):25592566.

6. Snell RS. Clinical neuroanatomy. 7th ed. Baltimore: Lippincott Williams \& Wilkins; 2010. p 542.

7. Fitzgerald MJT, Gruener G, Mtui E. Clinical neuroanatomy and neuroscience. 5th ed. Philadelphia: Elsevier Saunders; 2007.

8. Frontera WR, Silver JK, Thomas D. Rizzo J. Essentials of physical medicine and rehabilitation: musculoskeletal disorder, pain, and rehabilitation. 2nd ed. Canada: Saunders Elsevier; 2008.

9. Duncan PW, Zorowitz R, Bates B, Choi JY, Glasberg JJ, Graham GD, et al. Management of adult stroke rehabilitation care: a clinical practice guideline. Stroke. 2005;36(9):e100-43.

10. Onel S. Dietary supplements: a definition that is black, white, and gray. American Journal of Law \& Medicine. 2005;31(23):341-8.

11. Saposnik G, Ray JG, Sheridan P, McQueen M, Lonn E. Homocysteine-lowering therapy and stroke risk, severity, and disability: additional findings from the HOPE 2 trial.
Stroke. 2009;40(4):1365-72.

12. Ntaios G,Savopoulos C, Grekas D, Hatzitolios A. The controversial role of B-vitamins in cardiovascular risk: an update. Arch Cardiovasc Dis. 2009;102(12):847-54.

13. Gahche J, Bailey R, Burt V, Hughes J, Yetley E, Dwyer J, et al. Dietary supplement use among US adults has increased since NHANES III (1988-1994). NCHS Data Brief. 2011;61:1-8.

14. BPPK. Riset Kesehatan Dasar (Riskesdas) 2007. Jakarta: Kemenkes RI. 2007.

15. Venketasubramanian N. The epidemiology of stroke in ASEAN countries - a review. Neurol J Southeast Asia. 1998;3:9-14.

16. Truelsen T, Begg S, Mathers C. The global burden of cerebrovascular disease. Global Burden of Disease. 2006. [cited 2013 November 9] Available from: http:// www.who.int/healthinfo/statistics/bod_ cerebrovasculardiseasestroke.pdf

17. Kemenkes RI. Keputusan Menteri Kesehatan Indonesia Nomor 263/Menkes / SK/II/2010 Tentang Pedoman Rehabilitasi Kognitif. Jakarta: Kemenkes RI; 2010.

18. Ayranci U, Son N, Son O. Prevalence of nonvitamin, nonmineral supplement usage among students in a Turkish university. BMC Public Health. 2005;5:47.

19. Bhatti IU, Rehman FU, Khan MA, Marwat SK. Effect of Propheitic Medicine Kalonji (Nigella sativa L.) On lipid profile of human beings: an in vivo approach. World Appl Sci J. 2009;6(8):1053-7.

20. Foster S, Varoo E, Tyler P. Tyler's honest herbal a sensible guide to the use of herbs and related remedies. 4th ed. New York: The Hawsworth Press, Inc. 1999. 